\title{
Gelpey, Hamers, Muralt, and Orme to Chair 2008 MRS Spring Meeting
}

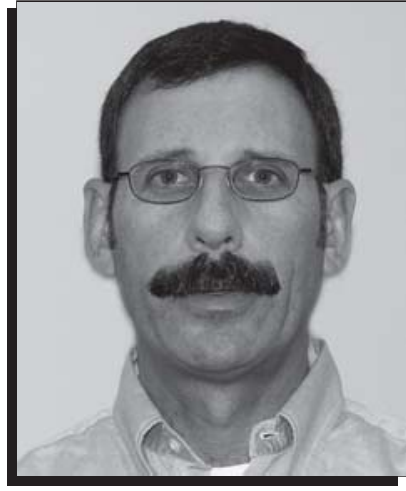

Jeffrey C. Gelpey

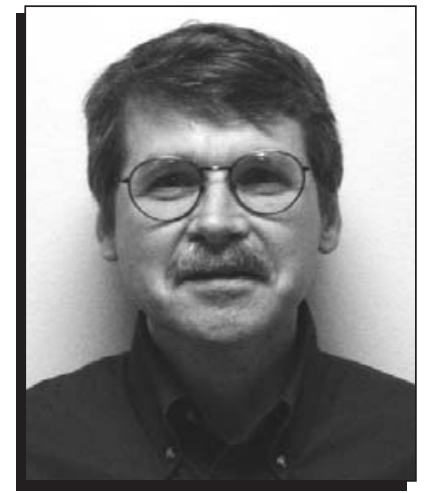

Robert J. Hamers

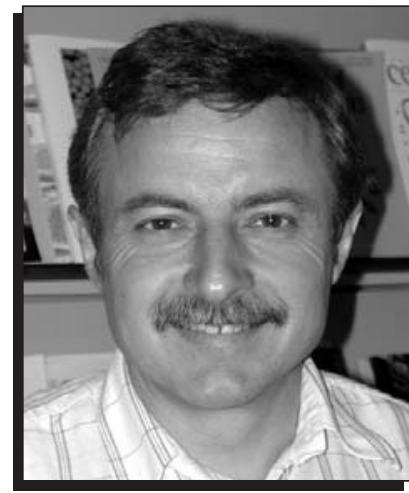

Paul Muralt

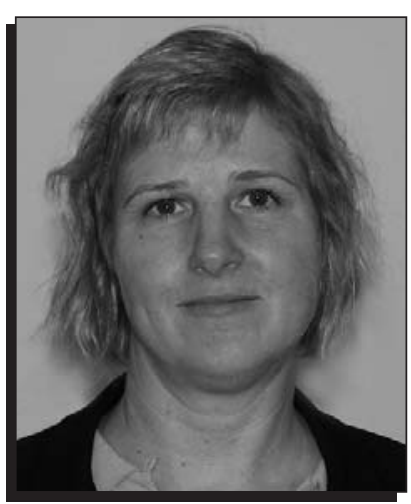

Christine A. Orme
Meeting Chairs for the 2008 Materials Research Society (MRS) Spring Meeting are Jeffrey C. Gelpey (Mattson Technology), Robert J. Hamers (University of Wisconsin-Madison), Paul Muralt (Swiss Federal Institute of Technology), and Christine A. Orme (Lawrence Livermore National Laboratory). The meeting will be held in San Francisco March 24-28, 2008.

Jeffrey C. Gelpey is currently a Fellow at Mattson Technology, Inc. working mostly on Mattson's fRTPTM ms annealing technology. He holds an MSEE and BSEE degree from the Massachusetts Institute of Technology in the area of solid-state physics. Gelpey started working as a process engineer for III-V and II-VI semiconductors at Honeywell. In 1981 he moved to the field of semiconductor processing equipment with work at Eaton (now Axcelis) on ion implantation and rapid thermal processing (RTP). He has worked in the RTP field for almost 25 years at Mattson and its predecessor companies (Vortek, STEAG, and AST Elektronik) as well as at Peak Systems and Eaton. His roles have involved equipment design, process development, and marketing. Gelpey is mainly involved in the development and bringing to market an advanced millisecond annealing tool for ultrashallow junction formation. He has been an MRS member since 1981 and has organized several symposia for MRS, the Electrochemical Society, and the Institute of Electrical and Electronics Engineers International Conference on Advanced Thermal Processing of Semiconductors Conference.

Robert J. Hamers is the Irving Shain Professor of Chemistry at the University of Wisconsin-Madison. Hamers received his BS degree in chemistry from the University of Wisconsin-Madison, and MS and PhD degrees in physical chemistry from Cornell University. Following completion of his doctoral work in 1985, he became a postdoc (1985-1986) and Research Staff Member (1986-1990) at the IBM T.J. Watson Research Center in Yorktown Heights, N.Y. In 1990, he left IBM to accept a faculty position at the University of Wisconsin-Madison, where he was promoted to full professor in 1994 and currently holds the Irving Shain Chair. Hamers has coauthored more than 180 publications in scanning tunneling microscopy, chemical reactivity and electronic properties of semiconductor and metal surfaces, and biomaterials interfaces. His awards include an NSF Presidential Faculty Fellowship, Peter Mark Award of the American Vacuum Society (AVS), John Simon Guggenheim Memorial Fellowship, and the Arthur Adamson Award of the American Chemical Society. He is a Fellow of the AVS and of the American Association for the Advancement of Science, and in addition to the MRS, he is a member of the American Chemical Society, the AVS Science and Technology Society, and the American Physical Society.

Paul Muralt holds a diploma in experimental physics (1978) and a ScD degree (1984) for works in solid-state physics, both of the Swiss Federal Institute of Technology ETH in Zurich. Before joining the Ceramics Laboratory of the Swiss Federal Institute of Technology EPFL in Lausanne in 1993, he was a Postdoctoral Fellow at IBM Research Laboratory in Zurich (1984-1985), worked briefly at the Free University of Berlin, and joined the Balzers group in Liechtenstein (1987). Muralt accomplished pioneering work in $\mathrm{Pb}(\mathrm{Zr}, \mathrm{Ti}) \mathrm{O}_{3}$ and $\mathrm{AlN}$ thin film devices. His research interests are in thin film growth and integration issues of ferroelectric and other polar materials, propertymicrostructure relationships, and applications of polar materials in semiconductor and microelectromechanical devices, including fabrication and property assessment of small ferroelectric structures. He authored or co-authored 190 scientific articles. He is senior member of the Institute of Electrical and Electronics Engineers and an MRS member. His awards include an outstanding achievement award from the International Symposium on Integrated Ferroelectrics.

Christine A. Orme is a physicist within the Chemistry Materials and Life Science directorate of Lawrence Livermore National Laboratory. She studied physics at the University of Michigan, receiving her PhD degree in 1995 in the area of surface evolution during vapor deposition. In 1996, she joined Lawrence Livermore National Laboratory where she has served as a project leader, group leader, and institute director. Orme's laboratory explores molecular processes at interfaces and uses in situ tools to address how these modify the way that materials assemble and disassemble. She is particularly interested in biomineralization, biomimetic approaches to materials assembly, corrosion, andunderlying all of these-the fundamental physics of growth and dissolution. She currently studies metalorganic interactions to understanding how ligands direct shape control during synthesis. She is a member of the Institute for Complex Adaptive Matter and has been a volume organizer for MRS Bulletin. She is the recipient of a Science and Technology Award from Lawrence Livermore National Laboratory (2001), an Office of Science Early Career Scientist and Engineer Award (2002), and a Presidential Early Career Award in Science and Engineering (2002) for her work in biomineralization.

For updated information on the 2008 MRS Spring Meeting, access Web site www.mrs.org/meetings/. 